\title{
Microaggressions and Objectivity: Experimental Measures and Lived Experience
}

\author{
Mikio Akagi ${ }^{\dagger+}$ \\ John V. Roach Honors College, Texas Christian University \\ Frederick W. Gooding, Jr. \\ John V. Roach Honors College, Texas Christian University
}

Microaggressions are, roughly, acts or states of affairs that express prejudice or neglect toward oppressed group members in relatively subtle ways. There is an apparent consensus among both proponents and critics of the MICROAGGRESSION concept that microaggressions are "subjective." We examine what subjectivity amounts to in this context and argue against this consensus. We distinguish between microaggressions as an explanatory posit and microaggressions as a hermeneutical tool, arguing that in either case there is no reason at present to regard microaggressions as subjective, and that microaggressions in the hermeneutical sense should be regarded as objective.

1. Introduction. The MICROAGGRESSION concept has received much attentionboth scholarly and popular-over the last decade. Microaggressions are, roughly, acts (often but not exclusively speech acts) that exhibit prejudice or neglect toward members

\footnotetext{
$\dagger$ To contact the authors, please write to: Texas Christian University, TCU Box 297922, Fort Worth, Texas 76129; email: m.akagi@tcu.edu.

$\$$ This paper is the result of ongoing discussions between the authors; Mikio Akagi is responsible for writing the first draft and for many of the ways ideas are expressed in the paper; Frederick Gooding was involved in many stages of planning, discussion, and revision. We thank, for their input and encouragement: Karen Kovaka, Nicholas Zautra, Rob Garnett, Andrew Ryder, and participants at the inaugural conference of the Mid/South Philosophy of Science Network and at the TCU Interdisciplinary Works in Progress talk series.
}

This is a preprint. Final version to be published in Philosophy of Science. 
of oppressed groups, or states of affairs that exclude or denigrate members of oppressed groups. There appears to be a consensus that microaggressions are "subjective," both among the concept's scientific proponents, such as Derald Wing Sue, and its critics, such as Scott O. Lilienfeld. Presumably, the claim that microaggressions are "subjective" means that there is no perspective-independent matter of fact regarding whether an act or state of affairs is a microaggression. That is, whether an act or state of affairs counts as a microaggression depends upon how it is perceived by some subject. We disagree with this consensus, distinguishing between "explanatory" and "hermeneutical" MICROAGGRESSION concepts. We argue that there is no a priori reason to regard explanatory microaggressions as "subjective," and that there are compelling phenomenological reasons to regard hermeneutical microaggressions as objective.

2. Microaggressions and their effects. The term "microaggression" was coined by African American psychiatrist Chester Pierce (1970) as a label for subtle forms of hostility or disdain commonly exhibited by White Americans against African Americans. The term was subsequently amplified by psychologist Derald Wing Sue and colleagues (Sue et al. 2007), who generalized the concept to encompass many subtle forms of racism. Their oft quoted gloss is that:

Racial microaggressions are brief and commonplace daily verbal, behavioral, and environmental indignities, whether intentional or unintentional, that communicate hostile, derogatory, or negative racial slights and insults to the target person or group. (Sue et al. 2007, 273)

The term is now understood broadly, both in critical theory and in psychology, as including not only racial slights, but also those related to gender (Capodilupo et al. 2010; Barthelemy et al. 2016), LGBTQ oppression (Nadal, Rivera, et al. 2010), disability (Keller and Galgay 2010; Gonzalez et al. 2015), socioeconomic status (Smith and Redington 2010), religion (Nadal, Issa, et al. 2010), or indeed any form of structural oppression (Sue 2010c), including intersectional forms of oppression (q.v. Crenshaw 1989; Nadal et al. 2015; Olkin et al. 2019). A person or social group that is demeaned or alienated by a microaggression is called a target. For microaggressions that are acts, the agent of the microaggression is generally called a perpetrator or performer.

A commonly-cited example of a verbal microaggression (e.g. in Sue 2010a; Lilienfeld 2017) is a remark made by John McCain during his 2008 presidential campaign against Barack Obama. A woman at a town hall event said to McCain that 
she doesn't trust Obama because "He's an Arab." McCain replied, "No ma’am. He's a decent family man, citizen, that I just happen to have disagreements with on fundamental issues... He's not." McCain's reply carries the unfortunate (and probably unintentional) conversational implicature that being of Arab descent counts in some way against being "a decent family man" or a "citizen." As such, it is an ethnic microaggression. Many microaggressions carry such implicatures, which are referred to in the microaggression literature as hidden messages (Sue et al. 2007). One of the challenges for researchers who generalize the MICROAGGRESSION concept to new domains of oppression is the identification of the relevant hidden messages (Johnston and Nadal 2010). Microaggressions can also be nonverbal acts, e.g. tightly clutching one's purse or crossing the street when encountering a Black man. And microaggressions can be states of affairs, such as the persistence of a problematic monument. Sue and colleagues (2007) call these latter states of affairs environmental microaggressions.

Some (e.g. Greg Lukianoff and Jonathan Haidt and other critics of "campus culture") suggest that the proper response to microaggressions is to toughen up or "grow a thicker skin." As Regina Rini notes, this may be an appropriate response to mere insults but it is an insufficient response to microaggressions because microaggressions are components of larger patterns of systematic oppression (2018). The targets of microaggressions are necessarily oppressed groups or their members. Of course slights can target privileged social groups or their members (e.g. "White people can't dance"), but such slights are not called "microaggressions" because they are not likely to have the same negative effects. ${ }^{1}$ The relevant difference between microaggressions and other slights is that microaggressions are congruent with oppressive systems, in Liao and Huebner's $(2020,10)$ sense, and therefore are smaller extensions of larger power structures. Slights that target privileged social groups go against the grain of oppressive social systems rather than being congruent with them.

Rini's reply is underappreciated in many skeptical discussions of microaggressions, including Lilienfeld's (2017), which raises doubts about whether the acts called microaggressions are always performed with malicious motivations. Performers' motivations may be relevant for assigning blame (see Washington and Kelly 2016 for

\footnotetext{
${ }^{1}$ We recognize standard provisos here: individual persons can be members both of oppressed and privileged social groups; e.g. a wealthy queer person may experience structural disadvantage related to their queerness but privilege related to their socioeconomic class. And oppression often compounds in a non-additive manner for those who are members of multiple oppressed social groups, e.g. Black women in the U.S. experience specific challenges faced neither by Black men nor by White women (Crenshaw 1989).
} 
discussion), but not for understanding the effects of microaggressions on their targets. Much of the psychological literature on microaggressions should be understood as part of what Nyla Branscombe and colleagues call the "psychology of the historically disenfranchised" $(1999,135,146)$ : empirical investigations that focus on the psychology of oppressed social groups rather than, like much of the implicit bias literature, the mental states of those who are privileged.

And it is hypothesized that the aggregate effect of microaggressions-perceived or otherwise-on their targets is significant, and not only because they cause gratuitous pain or discomfort. Perceived discrimination regarding race, gender, and sexual orientation predicts psychological and somatic health outcomes (Mays et al. 2007; Carter 2007; Herek 2009). Racial gaps in health outcomes in the U.S. are not fully explained by differences in socioeconomic status or self-esteem (Gee et al. 2007a, 2007b). Plausibly, microaggressions play a role in explaining these recalcitrant health gaps, and many discussions of microaggressions are motivated by appeal to various outcome gaps (in health, academic or professional achievement, etc.). The detailed mechanism by which microaggressions contribute to such outcome gaps is not known (Okazaki 2009; Torres et al. 2010), but stress seems to be a mediating factor (Harrell and Taliaferro 2003), complicated by in-group identification, which seems to have a protective effect (Crocker and Major 1989; Branscombe et al. 1999). The scientific situation is made more complicated by the multiplicity of experimental protocols (Sullivan 2009): since microaggression incidence is measured in a variety of ways, experimental inference about microaggressions is complicated in ways that are played down in published literature. And in some discussions, "microaggression" may function as a catchall term referring to any manifestations of structural oppression that are relatively difficult to measure independently.

So in the interest of promoting a little more clarity, we distinguish two MICROAGGRESSION concepts. The explanatory MICROAGGRESSION concept refers, ex hypothesi, to some factor that explains recalcitrant gaps in desirable outcomes (e.g. good health, professional success) between members of privileged and oppressed social groups, such as those that remain after other factors like wealth, income, and legal discrimination are accounted for. Microaggressions in this sense may turn out to be a variety of diverse factors (they may be "lumpy"; see Feest 2020); we will not know exactly what they look like until we have a more sophisticated causal understanding of recalcitrant outcome gaps. But the term "microaggression" functions in some discourse as a more determinate label for concrete experiences of slights and invalidations. So, let the hermeneutical MICROAGGRESION concept be what is invoked in such contexts. 
The hermeneutical MICROAGGRESSION concept is a hermeneutical resource (Fricker 2007) that helps people to make sense of their lived experiences, and the popularity of the MICROAGGRESSION concept outside of the behavioral and social sciences is probably largely due to its hermeneutical role. It is an open empirical question whether the explanatory and hermeneutical MICROAGGRESSION concepts are largely coextensive.

3. Two senses of "subjective." So are microaggressions objective? The answer depends on whether we are talking about explanatory or hermeneutical microaggressions. But clarification is also in order regarding the terms "objective" and "subjective." Philosophers tend to reserve the term "subjective" for propositions whose truth values vary according to a perspective (MacFarlane 2014: a "context of assessment"). For example, a dress may look blue and black to me, and may look white and gold (i.e. not-blue-and-black) to you. There is a perspective-independent fact about what color the dress is, but no such fact about how the dress looks; it looks different to different people. Let us call such claims alethically subjective, and claims that have perspective-independent truth values can be called alethically objective.

By contrast, in common parlance a claim is often said to be "subjective" if reasonable people disagree about its truth value, even if the claim has a perspectiveindependent truth value. We may call claims that are controversial in this manner discursively subjective. The claim that Shakespeare's works were written by William Shakespeare is discursively subjective-some folks believe the plays and poems were written by someone else. But there is a perspective-independent fact of the matter about who wrote Shakespeare's works, so the claim is not alethically subjective. ${ }^{2}$ Both alethic and discursive subjectivity are properties of claims rather than concepts or words, but for ease of expression we will talk about "microaggressions" as subjective or objective, meaning that classifying an act or state of affairs as a microaggression is subjective or objective.

Now, obviously claims about microaggressions can be discursively subjectivethere is often disagreement about whether a particular act or state of affairs is a microaggression. Nevertheless, it is commonly held that microaggressions are also alethically subjective. Lilienfeld criticizes the microaggression concept on the grounds

\footnotetext{
${ }^{2}$ Another sense of "objectivity" relevant to science is independence from values or normative commitments, but most microaggressions research is plausibly not objective in this sense since it presupposes a normative theory of justice and structural oppression. However, discussion of the value-free ideal in the social sciences is beyond the scope of our argument.
} 
that microaggressions are thought to be "necessarily in the eye of the beholder" (2017, 143), and Sue claims that "Microaggressions are about experiential reality" (2017, 171). Lilienfeld regards the subjectivity of microaggressions as a source of confusion:

If Minority Group Member A interprets an ambiguous statement directed toward her [...] as patronizing or indirectly hostile, whereas Minority Group Member B interprets it as supportive or helpful, should it be classified as a microaggression? The [microaggressions] literature offers scant guidance in this regard. (Lilienfeld 2017, 143)

Generally speaking, that a claim is discursively subjective does not imply that it alethically subjective (e.g. the Shakespeare case above is discursively subjective but not alethically subjective). So even if there is reasonable disagreement about whether a particular act or state of affairs is a microaggression, that does not imply that the microaggression is alethically subjective.

Lilienfeld continues:

it is unclear whether any verbal or nonverbal action that a certain proportion of minority individuals perceive as upsetting or offensive would constitute a microaggression. Nor is it apparent what level of agreement among minority group members would be needed to regard a given act as a microaggression. (Lilienfeld 2017, 143)

Such questions are unmotivated. No serious proponent of the MICROAGGRESSION concept holds that poll results should determine which acts are microaggressions. While "focus groups" and similar methods are sometimes used to determine which kinds of acts should be regarded as microaggressions (e.g. the use of Consensual Qualitative Research methods in Nadal et al. 2015), researchers do not assume that intersubjective agreement among participants is a criterion for being a microaggression. Rather, "focus group" methods are generally employed as techniques for discovering new varieties of microaggression while minimizing the role of researcher biases (see e.g. Nadal et al. 2015, 150-151).

Furthermore, as we argue below, there is no a priori reason to regard microaggressions as alethically subjective. Regarding explanatory microaggressions, it is an open empirical question whether outcome gaps are explained by perceived microaggressions or by microaggressions regardless of how they are perceived by their targets (i.e. microaggressions ascribed according to an alethically subjective or objective 
criterion), or by some other factor. Regarding hermeneutical microaggressions, the concept fails to serve as an adequate hermeneutical resource unless microaggressions are regarded as objective.

\section{Explanatory microaggressions: measures and constructs. Lilienfeld} observes that most microaggression studies rely on self-report measures, and takes this to be a consequence of the fact that microaggressions are alethically subjective (2017, 151). For example, many studies of microaggressions against African Americans use an instrument called the Daily Life Experiences (DLE) scale (e.g. Scott 2003; Seaton et al. 2009; Torres et al. 2010), developed by Jules Harrell. The instrument consists of 17-20 items describing discriminatory experiences, such as "overhearing or being told an offensive joke" or "being left out of conversations or activities" (from Seaton et al.). Study participants rate how often they have each kind of experience on a scale from "never in the past year" to "once a week or more." Their responses are analyzed (in various ways, depending on the study) to obtain a quantity representing how often participants experience racial microaggressions. The DLE scale is a so-called "selfreport" or "subjective" measure, since study participants more or less transparently report information in which experimenters are interested for its own sake (in contrast to behavioral measures or other indirect measures). Self-report measures are common in psychological research on "subjective" constructs like subjective well-being (Alexandrova 2008) or conscious visual experience (Boone 2013), where a "construct" in psychology is a theoretical term whose quantity can be measured (Stone 2019, 1250 n2).

However, the connection between subjective constructs and so-called "subjective measures" is not straightforward. An experimental measure will generally differ from its associated construct in various ways. For example, a Stroop test may be administered as a measure of cognitive depletion (as in e.g. Richeson and Trawalter 2005). But Stroop performance is a temporal measure (a relative delay, measured in milliseconds) whereas cognitive depletion is theoretically something more abstract: it may manifest as a temporal delay or as poorer performance or in various other ways. So here a temporal measure is used to approximate, for the purposes of experimental analysis, the quantity of a more abstract construct of interest (cognitive depletion).

More to the current point, self-report measures may be used to gather information about constructs whose values are alethically objective. Consider, for example, the Perceptual Awareness Scale (PAS), a graded measure of visual awareness (Ramsøy and Overgaard 2004). Study participants are briefly shown an image (often for less than 250 
ms) and asked to classify their visual experience as "Clear Image," "Almost Clear Image," Weak Glimpse," or "Not Seen." One may think that this is a subjective measure for a subjective construct, since visual experience is often said to be "subjective," but alethic subjectivity is a property of claims so we must be precise about what claim is at issue. Visual experience is subjective in that the content of two visual experiences may differ for various judges (or one judge at different times) although those experiences are of the same object in the same conditions. We often characterize the contents of such experiences using clauses with "seem" or "look" as the main verb, and such clauses are alethically subjective. A dress may look blue to Ali and at the same time look white (i.e. not-blue) to Leah; the truth value of an utterance like "This dress looks blue" may vary depending on the judge. But the PAS does not measure what the content of a visual experience is; the PAS measures whether a visual experience of a stimulus occurred for a particular observer, and how clear that experience was. This is an alethically objective state of affairs. The truth value of "Ali had a clear visual experience of the stimulus" does not vary according to who evaluates it. If Ali and Leah disagree about the truth of such a sentence, then one of them must be wrong (and it's probably not Ali).

Similarly, instruments like the DLE scale, which purport to reveal rates of microaggression incidence in a participant's life through self-report, may be fallible measures of an alethically objective quantity. We say "may" because much extant microaggression research does not distinguish clearly between alethically objective and subjective interpretations of microaggression incidence. Instruments like the DLE scale may be used either to measure the frequency of a participant's exposure to demeaning incidents (an alethically objective quantity), or to measure the participant's perception of how often she experiences demeaning incidents (an alethically subjective quantity). Microaggressions in the explanatory sense are some factor that explains recalcitrant gaps in desirable outcomes between members of privileged and oppressed social groups, such as those that remain after other factors like wealth, income, and legal discrimination are accounted for. It is an open question whether this factor is (1) mere exposure to demeaning incidents, regardless of how they are perceived by their targets, or (2) the perception of one's experiences as demeaning, or (3) something else. That is, it is an open empirical question whether explanatory microaggressions are alethically objective or subjective. Further empirical study is needed to assess the relative merits of these hypotheses.

As a matter of verbal hygiene, it seems reasonable to us to treat explanatory microaggressions as alethically objective, and then to examine whether outcome gaps are caused by exposure to microaggressions per se or by the perception of events as 
microaggressions. By analogy, the standard for whether an act is a sexual assault is not whether the survivor characterizes the act as "sexual assault" or even as harmful. But the matter of which way to speak can only be settled by the community of speakers (in this case, the community of social and behavioral scientists), not by fiat, and it seems to us that the matter has not yet been settled.

We wish to be clear that microaggression research employs a variety of methods that vary in quality and purpose; the DLE scale is only one instrument among many. Our main objective here is not to conduct a methodological review (for which see e.g. Okazaki 2009; Lau and Williams 2010; Wong et al. 2014), but to argue against a tempting error. It is simplistic to identify a construct with its measure, and it is an error to freely attribute the properties of a measure to its associated construct. So while it is true that microaggression frequency is often measured using participant self-reports, we should not infer from this fact that microaggression incidence is alethically subjective. Existing measurement practices do not settle the question of whether microaggressions are "in the eye of the beholder."

\section{Hermeneutical microaggressions: phenomenological considerations.}

Whereas it is an open question whether explanatory microaggressions are alethically subjective, there is compelling reason to regard hermeneutical microaggressions as alethically objective. Our argument depends on the commonly reported phenomenology of microaggression targets. Members of oppressed groups often report experiencing confusion and uncertainty about whether an act directed toward them is a subtle expression of prejudice, or whether it is no different than an act that would have been directed toward a privileged person. This feature of microaggressions is sometimes called "attributional ambiguity" (Crocker and Major 1989). For example, a woman might be addressed at work by her first name (e.g. "Stephanie") rather than by her title and surname (say, "Dr. Appiah"). In a context where either form of address is acceptable, and where the base rates are not known (i.e. it is not known how often people in general, or people of various genders, are addressed by their first names vs. by their titles and surnames), it can be difficult to determine whether the address expresses a slight.

Here is an argument that we should consider hermeneutical microaggressions to be alethically objective. Supposing the contrary, that microaggressions are alethically subjective, there are two possibilities. First, perhaps, as in many matters of taste, it is appropriate to allow everyone their own perspective. So whoever feels the act of addressing the woman by her first name was a gendered slight regards it as a 
microaggression, and whoever feels the form of address was not influenced by gender does not regard it as a microaggression. If microaggressions are alethically subjective, as we are currently supposing, then there is no perspective-independent fact of the matter about whether this incident is a microaggression (as in predications of "is tasty" or "looks blue-ish to me"). A second possibility is that people have their own perspectives but the target's perspective is decisive: the act is a microaggression if and only if the addressed woman feels slighted. In both of these possibilities, it makes no sense for the woman to wonder whether the act was really an expression of prejudice, i.e. whether it was really a microaggression. On the first option, there is no fact of the matter about whether the act was a microaggression. On the second option, the matter is decided by the woman's own perspective, so her judgment settles the question.

However, people who experience relatively subtle microaggressions often report wondering precisely about this. Indeed, it is often claimed (e.g. by Sue et al. 2007; Bartky 1975; Du Bois 1903 and others) that much of the harm of microaggressions is caused precisely by anxiety and paranoia regarding one's inability to quickly and accurately assess whether an act was indeed a microaggression. Only the objectivist view of microaggressions accounts for this phenomenology. If we seek hermeneutical justice, we have reason to adopt concepts that make sense of rather than obscure common experiences for members of oppressed social groups (Fricker 2007). So we should regard microaggressions as objective, in that there are perspective-independent facts about whether particular acts or states of affairs are microaggressions in the hermeneutical sense.

6. Conclusion. We argued, against the common view, that microaggressions should not be regarded as alethically subjective. For microaggressions in the hermeneutical sense-considered as a category of items that help members of oppressed social groups to make sense of their lived experience-we argue that only an objectivist view rationalizes the distress commonly experienced due to attributional ambiguity. For microggressions in the explanatory sense-considered as the causes of recalcitrant outcome gaps-we acknowledge that it is an open question whether they are best regarded as alethically objective or subjective. But we argued against a tempting view, expressed by Lilienfeld and others, that self-report measures are especially suited for measuring the value of theoretical constructs that are alethically subjective. People will continue to question whether particular acts or states of affairs count as 
microaggressions, and we contend that those questions have objectively accurate responses.

\section{REFERENCES}

Alexandrova, Anna. 2008. "First-Person Reports and the Measurement of Happiness." Philosophical Psychology 21: 571-583.

Barthelemy, Ramón S., Melinda McCormick, and Charles Henderson. 2016. "Gender Discrimination in Physics and Astronomy: Graduate Student Experiences of Sexism and Gender Microaggressions." Physical Review Physics Education Research 12 (o20119): 1-14.

Bartky, Sandra Lee. 1975. "Toward a Phenomenology of Feminist Consciousness." Social Theory and Practice 3: 425-439.

Boone, Worth. 2013. "Operationalizing Consciousness: Subjective Report and Task Performance." Philosophy of Science 80: 1031-1041.

Branscombe, Nyla R., Michael T. Schmitt, and Richard D. Harvey. 1999. "Perceiving Pervasive Discrimination among African Americans: Implications for Group Identification and Well-Being." Journal of Personality and Social Psychology 77: 135-149.

Capodilupo, Christina M., Kevin L. Nadal, Lindsay Corman, Sahran Hamit, Oliver B. Lyons, and Alexa Weinberg. 2010. "The Manifestation of Gender Microaggressions." In Sue 2010b, 193-216.

Carter, Robert T. 2007. "Racism and Psychological and Emotional Injury: Recognizing and Assessing Race-Based Traumatic Stress." The Counseling Psychologist 35: 13-105.

Crenshaw, Kimberle. 1989. "Demarginalizing the Intersection of Race and Sex: A Black Feminist Critique of Antidiscrimination Doctrine, Feminist Theory and Antiracist Politics." University of Chicago Legal Forum 1989: 139-167.

Crocker, Jennifer, and Brenda Major. 1989. "Social Stigma and Self-Esteem: The Self-Protective Properties of Stigma." Psychological Review 96: 608-630.

Du Bois, W.E.B. 1903. The Souls of Black Folk. Chicago: McClurg.

Feest, Uljana. 2020. "Construct Validity in Psychological Tests - the Case of Implicit Social Cognition." European Journal for Philosophy of Science 10. https://doi.org/10.1007/s13194019-0270-8.

Fricker, Miranda. 2007. Epistemic Injustice: Power and the Ethics of Knowing. Oxford: Oxford University Press.

Gee, Gilbert C., Michael Spencer, Juan Chen, Tiffany Yip, and David T. Takeuchi. 2007a. "The Association between Self-Reported Racial Discrimination and 12-Month Dsm-Iv Mental Disorders among Asian Americans Nationwide." Social Science and Medicine 64: 19841996.

- - 2007b. "A Nationwide Study of Discrimination and Chronic Health Conditions among Asian Americans." American Journal of Public Health 97: 1275-1282.

Gonzalez, Lauren, Kristin C. Davidoff, Kevin L. Nadal, and Philip T. Yanos. 2015. "Microaggressions Experienced by Persons with Mental Illness: An Exploratory Study." Psychiatric Rehabilitation Journal 38: 234-241.

Harrell, Jules P., and James Taliaferro. 2003. "Physiological Responses to Racism and Discrimination: An Assessment of the Evidence." American Journal of Public Health 93: 243-248. 
Herek, Gregory M. 2009. "Hate Crimes and Stigma-Related Experiences among Sexual Minority Adults in the United States: Prevalence Estimates from a National Probability Sample." Journal of Interpersonal Violence 24: 54-74.

Johnston, Marc P., and Kevin L. Nadal. 2010. "Multiracial Microaggressions: Exposing Monoracism in Everyday Life and Clinical Practice." In Sue 2010b, 123-144.

Keller, Richard M., and Corinne E. Galgay. 2010. "Microaggressive Experiences of People with Disabilities." In Sue 2010b, 241-267.

Lau, Michael Y., and Chantea D. Williams. 2010. "Microaggression Research: Methodological Review and Recommendations." In Sue 2010b, 313-336.

Liao, Shen-yi, and Bryce Huebner. 2020. "Oppressive Things." Philosophy and Phenomenological Research. https://doi.org/10.1111/phpr.12701.

Lilienfeld, Scott O. 2017. "Microaggressions: Strong Claims, Inadequate Evidece." Perspectives on Psychological Science 12: 128-169.

MacFarlane, John. 2014. Assessment Sensitivity: Relative Truth and Its Applications. Oxford: Clarendon.

Mays, Vickie M., Susan D. Cochran, and Namdi W. Barnes. 2007. "Race, Race-Based Discrimination, and Health Outcomes among African Americans." Annual Review of Psychology 58: 201-225.

Nadal, Kevin L., Kristin C. Davidoff, Lindsey S. Davis, Yinglee Wong, David Marshall, and Victoria McKenzie. 2015. "A Qualitative Approach to Intersectional Microaggressions: Understanding Influences of Race, Ethnicity, Gender, Sexuality, and Religion." Qualitative Psychology 2:

147-163.

Nadal, Kevin L., Marie-Anne Issa, Katie E. Griffin, Sahran Hamit, and Oliver B. Lyons. 2010. "Religious Microaggressions in the United States: Mental Health Implications for Religious Minority Groups." In Sue 2010b, 287-310.

Nadal, Kevin L., David P. Rivera, and Melissa J.H. Corpus. 2010. "Sexual Orientation and Transgender Microaggressions: Implications for Mental Health and Counseling." In Sue 2010b, 217-240.

Okazaki, Sumie. 2009. "Impact of Racism on Ethnic Minority Mental Health." Perspectives on Psychological Science 4: 103-107.

Olkin, Rhoda, H’Sien Hayward, Melody Schaff Abbene, and Goldie VanHeel. 2019. "The Experiences of Microaggressions against Women with Visible and Invisible Disabilities." Journal of Social Issues 75: 757-785.

Pierce, Chester. 1970. "Offensive Mechanisms." In The Black Seventies, edited by Floyd B. Barbour, 265-282. Boston: Porter Sargeant.

Ramsøy, Thomas Zoëga, and Morten Overgaard. 2004. "Introspection and Subliminal Perception." Phenomenology and the cogntiive sciences 3: 1-23.

Richeson, Jennifer A., and Sophie Trawalter. 2005. "Why Do Interracial Interactions Impair Executive Function? A Resource Depletion Account." Journal of Personality and Social Psychology 88: 934-947.

Rini, Regina. 2018. "How to Take Offense: Responding to Microaggression." Journal of the American Philosophical Association 4: 332-351.

Scott, Lionel D. 2003. "The Relation of Racial Identity and Racial Socialization to Coping with Discrimination among African American Adolescents." Journal of Black Studies 33: 520538. 
Seaton, Eleanor K., Tiffany Yip, and Robert M. Sellers. 2009. "A Longitudinal Examination of Racial Identity and Racial Discrimination among African American Adolescents." Child Development 80: 406-417.

Smith, Laura, and Rebecca M. Redington. 2010. "Class Dismissed: Making the Case for the Study of Classist Microaggressions." In Microaggressions and Marginality: Manifestation, Dynamics, and Impact, edited by Derald Wing Sue, 269-285. Hoboken, New Jersey: Wiley.

Stone, Caroline. 2019. "A Defense and Definition of Construct Validity in Psychology." Philosophy of Science 86: 1250-1261.

Sue, Derald Wing. 2010a. Microaggressions in Everyday Life: Race, Gender, and Sexual Orientation. Hoboken, New Jersey: Wiley.

_- - ed. 2010b. Microaggressions and Marginality: Manifestation, Dynamics, and Impact. Hoboken, New Jersey: Wiley.

- - . 2010c. "Microaggressions, Marginality, and Oppression: An Introduction." In Sue 2010b, $3-22$.

- - 2017. "Microaggressions and "Evidence": Empirical or Experiential Reality?" Perspectives on Psychological Science 12: 170-172.

Sue, Derald Wing, Christina M. Capodilupo, Gina C. Tonino, Jennifer M. Bucceri, Aisha M.B. Holder, Kevin L. Nadal, and Marta Esquilin. 2007. "Racial Microaggressions in Everyday Life: Implications for Clinical Practice." American Psychologist 62: 271-286.

Sullivan, Jacqueline A. 2009. "On the Multiplicity of Experimental Protocols." Synthese 167: 511-539.

Torres, Lucas, Mark W. Driscoll, and Anthony L. Burrow. 2010. "Racial Microaggressions and Psychological Functioning among Highly Achieving African-Americans: A MixedMethods Approach." Journal of Social and Clinical Psychology 29: 1074-1099.

Washington, Natalia, and Daniel Kelly. 2016. "Who's Responsible for This? Moral Responsibility, Externalism, and Knowledge About Implicit Bias." In Implicit Bias and Philosophy, Volume 2: Moral Responsibility, Structural Injustice, and Ethics, edited by Jennifer Saul and Michael Brownstein. Oxford: Oxford University Press.

Wong, Gloria, Annie O. Derthick, E.J.R. David, Anne Saw, and Sumie Okazaki. 2014. "The What, the Why, and the How: A Review of Racial Microaggressions Research in Psychology." Race and social problems 6: 181-200. 